
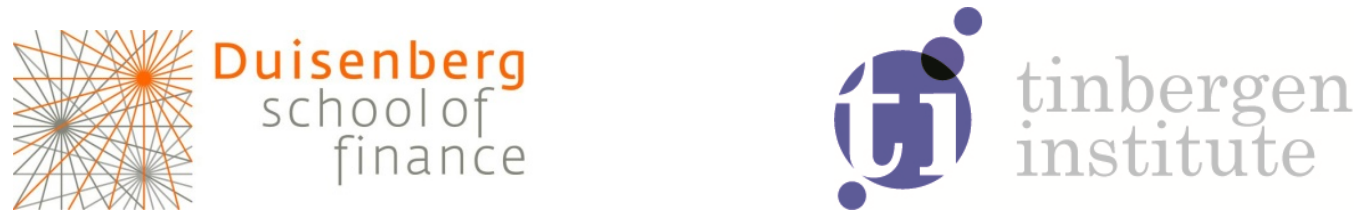

Duisenberg school of finance - Tinbergen Institute Discussion Paper

TI 14-137/IV/ DSF 81

\title{
Capital Structure Arbitrage revisited
}

\author{
Marcin Wojtowicz
}

Faculty of Economics and Business Administration, VU University Amsterdam, and Tinbergen Institute, the Netherlands. 
Tinbergen Institute is the graduate school and research institute in economics of Erasmus University Rotterdam, the University of Amsterdam and VU University Amsterdam.

More TI discussion papers can be downloaded at http://www.tinbergen.nl

Tinbergen Institute has two locations:

Tinbergen Institute Amsterdam

Gustav Mahlerplein 117

1082 MS Amsterdam

The Netherlands

Tel.: +31(0)205251600

Tinbergen Institute Rotterdam

Burg. Oudlaan 50

3062 PA Rotterdam

The Netherlands

Tel.: +31(0)10 4088900

Fax: +31(0)104089031

Duisenberg school of finance is a collaboration of the Dutch financial sector and universities, with the ambition to support innovative research and offer top quality academic education in core areas of finance.

DSF research papers can be downloaded at: http://www.dsf.nl/

Duisenberg school of finance

Gustav Mahlerplein 117

1082 MS Amsterdam

The Netherlands

Tel.: +31(0)20 5258579 


\title{
Capital structure arbitrage revisited*
}

\author{
Marcin Wojtowicz \\ VU University Amsterdam \\ Tinbergen Institute \\ m.p.wojtowicz@vu.nl \\ +31 20-598-2895
}

February, 2014

*I would like to thank Ton Vorst, Herbert Rijken and Philip Stork for discussions and suggestions. 


\title{
Capital structure arbitrage revisited
}

\author{
February, 2014
}

\begin{abstract}
We study risk and return properties of capital structure arbitrage strategies aiming to profit from temporal mispricing between equity and credit default swaps (CDSs) of companies. We find that capital structure arbitrage provides an attractive annualized return of $24.35 \%$ on invested capital. The arbitrage returns are higher for lower rated companies and surprisingly they are also higher for more liquid companies with larger CDS trading volumes. We find that the number of open arbitrage trades can at times cluster and in our sample the concentration of trades occurs when they are most profitable, which highlights the issue of capital allocation. Constructing weekly return indices of capital structure arbitrage, we find that no more than $15 \%$ of the returns is explained by common risk factors.
\end{abstract}

Keywords: capital structure arbitrage, credit defaults swaps, arbitrage.

JEL Classification: G11, G12, G14, G19 


\section{Introduction}

Capital structure arbitrage aims to profit from temporal mispricing between equity and bonds or credit default swaps of companies. This type of arbitrage grew in popularity around the turn of the century with the increasing size of the CDS market. The number of hedge funds using capital structure arbitrage has increased five-fold between the year of 2000 and 2005 reaching over 300 active funds near the end of $2005 .^{1}$ As a result capital structure arbitrage received much attention in academic literature, see among others, Yu (2006), Duarte et al. (2007), Bajlum and Larsen (2008) and Cserna and Imbierowicz (2008).

The idea behind capital structure arbitrage is that the market pricing of equity and debt can diverge away from equilibrium, which might be because different types of investors are active in each market and they possibly have different opinions about prospects of a company. Using an appropriately calibrated structural model an arbitrageur aims to predict what the fair CDS premium should be given the equity price and other parameters. If mispricing in the relative pricing between equity and CDS is detected, then depending on the direction of the mispricing an arbitrageur can either sell overvalued CDS protection and short equity as a hedge or buy undervalued CDS protection and buy equity. Of course an arbitrageur will only make a profit if the prices of the instruments subsequently revert towards equilibrium, so a successful implementation of the strategy requires identifying mispricings that are on average corrected over some reasonably short time-horizon.

In this paper, we analyze the risks and returns of capital structure arbitrage. We find that capital structure arbitrage provides a relatively large mean holding period return of $7.47 \%$ before transaction costs, which given the average holding period of 81 days translates into approximately $24.35 \%$ annualized return on invested capital. Throughout our analysis, we consider holding period returns both with and without accounting for transaction costs. We find that incorporating the bid-ask spreads reduces the returns only moderately. The mean holding period return after transaction costs is slightly lower at $6.59 \%$, but still substantial. We also find that approximately $60 \%$

\footnotetext{
${ }^{1}$ The cited number of hedge funds is obtained based on the TASS database by counting the number of funds active in capital structure arbitrage excluding funds of funds.
} 
of implemented trades end up in convergence, while over $65 \%$ of trades provide positive returns on the closure dates, which altogether provides a positive view on the profitability of this strategy. We further analyze the properties of the returns within different subsamples defined based on obligor characteristics. We find that returns on arbitrage for lower-rated companies and those with higher CDS premia provide greater returns. In particular, the group of cross-over companies rated BB-BBB, which constitutes almost $60 \%$ of the sample, offers an attractive mean holding period return of over $10 \%$. We also investigate the hypothesis that large arbitrage profits are driven by low liquidity, which causes slower price-discovery and hinders arbitrageurs' ability to execute trades due to low market depth etc. However, we find that the largest profits are obtained for the most liquid obligors, while the lowest profits are obtained for the least liquid obligors. We further split the sample into three groups categorized by weekly trading volume and find that the highest arbitrage profits are obtained within the group with the highest trading volume. Altogether, our results clearly show that arbitrage profits are not explained by any dimension of liquidity.

We also study the time-dimension of capital structure arbitrage returns. We find that while new trades are opened evenly over time, there is about 4.5 months in our data period of 29 months when very few existing trades are closed down and thus the number of open trades almost doubles relative to its fairly constant average level. This shows an important aspect of managing and allocating capital between arbitrage trades because insufficient capital of an arbitrageur can substantially reduce the achievable profits if profitable trades cluster in time. Indeed, we find that almost $70 \%$ of the total profits are made during the aforementioned 4.5 month period because that is when individual trades are also relatively much more profitable. The finding that trades are more profitable during the period when a larger number of arbitrage trade opportunities is available is not surprising because such profitable opportunities might be arising precisely because arbitrageurs have insufficient capital to implement trades that would realign the prices back to equilibrium. It can also be an explanation of why a mean holding period return of $6.59 \%$ after transaction costs is not arbitraged away by hedge funds. Altogether our results highlight the importance of the timedimension in assessing profitability of the arbitrage strategies, which has not been discussed in 
previous studies on capital structure arbitrage.

Finally, we construct indices tracking profitability of capital structure arbitrage and analyze whether they can be explained by common risk factors. We find that S\&P 500 returns and the Bank of America Merill Lynch's indices tracking yields on BB and BBB rated bonds are significant in explaining capital structure arbitrage returns although the percentage of variation explained is below $15 \%$. Finally, we confirm that capital structure arbitrage returns are not related to dealer funding costs (TED spread) or marking volatility (VIX index) demonstrating that this arbitrage strategy is not driven by market stress or market volatility.

Our paper makes several contributions to the existing literature. Firstly, we analyze capital structure arbitrage in the very recent period from July 2010 to November 2012 when the CDS market was already highly developed. This is after the introduction of the CDS Big-Bang protocol and also other reforms of the CDS market as discussed in Section 1.1, which improved transparency, robustness and liquidity of this market. Most existing studies analyze the period when the CDS market was in its 'infancy' between 2002-2004 (e.g. Yu (2006), Bajlum and Larsen (2008)). Secondly, we compute transaction costs using detailed bid-ask spreads collected by Markit from actual trading offers sent by dealers to the buy-side clients, while the existing studies assume a 5\% relative bid-ask spread for the sample period between 2002-2004. We find that even in the 2010-2012 period actual bid-ask spreads are much larger than the 5\% assumed previously. Thirdly, most studies follow the methodology of $\mathrm{Yu}(2006)$ to calibrate parameters of the structural model used for deriving CDS premia levels by minimizing the squared deviations between the actual and modelderived CDS premia over the first 10 days in the sample. We explain that such an approach might introduce a large bias in the results and instead we use a rolling CDS-implied volatility estimator to identify temporary mispricings between the CDS and equity. Fourthly, we assume that whenever a large deviation between model-derived and market CDS premia arises, we implement a single arbitrage trade with a $\$ 5$ million notional, which is a realistic strategy for a financial institution to follow. The existing studies assume that a new trade is opened on every day as long as a deviation persists for a reference entity, which often results in hundreds of trades being opened for a single 
company. Fifthly, we are the first to analyze the profitability of trades across different subsamples based on many characteristics of CDS obligors, which allows us to gain more insight into risks and return of capital structure arbitrage. In particular, we find that arbitrage returns are not explained by low CDS liquidity that could be behind lower price efficiency and thus larger arbitrage profits. Sixthly, we provide a more detailed analysis of arbitrage trades along the time-dimension, which demonstrates that the number of open trades can significantly cluster in time and in our sample it clusters around the time when the largest profits are made. This highlights the importance of capital allocation across trades, which is likely to limit profits attainable to arbitrageurs. Finally, we find that the return indices are associated with the common risk factors, while the previous studies did not detect such relationship. We show that using a different method to construct capital structure return index allows for detecting a larger association between the index and common risk factors.

The rest of this paper is organized as follows. Section 1.1 discusses the related literature Section 2 presents our modeling approach and the CreditGrades model, while Section 3 explains how we construct trading strategies. Section 4 discusses the data. Section 5 presents the results of the empirical analysis. Section 6 concludes.

\subsection{Related literature}

This paper extends the literature on capital structure arbitrage. A major contribution in this area is by $\mathrm{Yu}(2006)$ who examines the risks and returns of capital structure arbitrage using the CreditGrades model based on a sample of North American firms covering the period between 2001 and 2004. Yu (2006) analyzes strategies in several specifications with different holding periods (30 or 180 days) and different trading-triggers based on whether a deviation between the market and model CDS spreads exceeds $50 \%, 100 \%$ or $200 \%$. A new trade is opened on every trading day when there is a trading-trigger deviation between the model and market spreads, so there can be multiple trades open for a single company. The trades are assumed to converge when the model and market spreads become equal.

$\mathrm{Yu}(2006)$ finds that individual capital structure arbitrage strategies are very risky with as few 
as $10 \%$ of all trades eventually converging. $\mathrm{Yu}(2006)$ also finds that while the mean holding period returns are negative or near-zero for the 30 day holding periods, they are positive for the 180 day strategy. The maximum mean holding period return of $2.78 \%$ is achieved for speculative grade obligors and the strategy using the 50\% trading deviation trigger. By aggregating the returns on individual trades into monthly excess return indices created by equal investments into each of the trades, the mean and median monthly returns are positive with the highest return of roughly $1 \%$ achieved for the speculative grade companies following the strategy based on a $100 \%$ trading deviation trigger. However, applying the test of statistical arbitrage by Hogan et al. (2004), $\mathrm{Yu}$ (2006) finds no evidence of significant arbitrage for any of the strategy specifications considered, likely because of a relatively short sample period of 48 months.

The paper of $\mathrm{Yu}$ (2006) has been extended by other authors in several dimensions. Bajlum and Larsen (2008) show that profitability of capital structure arbitrage is significantly higher when relative mispricing between equity and debt is identified using CreditGrades calibrated with optionimplied volatilities instead of historical volatilities. For example, they find that mean holding period returns for speculative grade obligors increase from $2.64 \%$ to $4.61 \%$ when switching from historical to option-implied volatilities. However, for investment grade firms, the increase in the return is much smaller. Overall, the results of Bajlum and Larsen (2008) are consistent with Cao et al. (2011) who demonstrate that calibration of CreditGrades model with option-implied volatilities provides significantly better fit to CDS market prices for a large sample of firms during the 2007-09 financial crisis.

Bajlum and Larsen (2008) also demonstrate that relying on the model of Leland and Toft (1996) with endogenous default threshold improves the profitability of capital structure arbitrage strategies, but the increase in returns is only of secondary importance compared to the increase achieved by using CreditGrades with option-implied volatilities instead of historical volatilities.

Duarte et al. (2007) conduct a broader analysis of fixed income arbitrage and consider capital structure arbitrage as one of the trading strategies. They consider the same specifications of capital structure arbitrage as $\mathrm{Yu}(2006)$ and find that trading strategies in five out of six specifications 
provide positive and significant (at the $10 \%$ level) alphas after transactions costs. In the case of four out of six strategies, positive alphas are still significant after controlling for several risk factors (among others the Fama-French factors) indicating that profits from capital structure are not merely compensation for systematic risk factors. Compared to other fixed income strategies, Duarte et al. (2007) find that capital structure arbitrage requires several times more capital to achieve the standard deviation of excess returns of $10 \%$. They also find that excess returns from capital structure arbitrage are positively skewed indicating that this strategy is not about "picking up nickels in front of a steamroller". Finally, Duarte et al.(2007) find that the correlation between their index of capital structure arbitrage returns and HRFI fixed income arbitrage index is 0.26 , while the correlation with CSFB/Tremont fixed income arbitrage index is slightly negative at -0.05 , which they suggest might be due to limited share of capital structure arbitrage in hedge fund activities in the sample period between 2001 to 2004 .

The capital structure arbitrage is related to the question of synchronicity and relative price discovery between equity, CDS and bond markets. That is because consistent profits from capital structure arbitrage can only arise when there is incomplete integration or different speed of price discovery between these markets. Blanco et al. (2005) investigate price discovery in the CDS market relative to the bond market and find that both markets are reasonably well integrated, in particular for US firms. When deviations in pricing do occur, they are typically corrected by adjustment of bond prices. Blanco et al. (2005) also find that the CDS market better reflects changes in firm-specific variables related to credit risk, while the bond market adjusts with a time-lag. That is likely due to greater liquidity of the CDS market and therefore using the CDS market in capital structure arbitrage is more cautious than using the bond market. Possible profits when using the bond market could be higher due to its arguably lower efficiency, but the traders' ability to profit from bond mispricing would be limited by liquidity considerations. Moreover, synthetic CDS markets makes it equally easy to take long and short positions, while shorting in bond markets is often constrained. The bond market is not well-standardized and most corporates have several bond issues with different characteristics such as maturity, seniority, fixed versus floating coupons 
as well as various clauses and covenants. The frequency of trading of individual bond issues and even bid-ask quote provision is therefore substantially lower compared to the CDS market, which is well-standardized.

As discussed in Wojtowicz (2013), the standardization of contracts in the CDS market has much improved in the recent years with implementation of a number of changes known as the CDS Big Bang in 2009 for the North American markets. These measures included introducing two fixed coupon levels for CDS contracts (one for investment grade obligors and one for high-yield obligors), fixed coupon dates, agreeing on the standard restructuring clause of no restructuring and settlement rules for defaulted entities. ${ }^{2}$ Also, most trades in the CDS market are for contracts with 5 year maturity. Altogether, Chen et al. (2011) finds that almost 50\% of all trades in the CDS universe conform to the standard restructuring clause and have a 5 year maturity implying that the CDS market is a more convenient venue for taking credit risk exposure than the corporate bond market. The CDS market has also evolved recently in response to its weaknesses demonstrated by the 2007-2009 financial crisis, in particular concerns about the counterparty risks, see Wojtowicz (2013) for an overview. The most important measure was the move towards central clearing and introduction of periodical trade compressions that replace existing contracts between dealers to reduce the number of contracts between dealers while preserving their net risk exposure.

Norden and Weber (2009) study the relationship between CDSs, bonds and stocks in the time period between 2000 and 2002 and find that equity prices lead both CDS and bond prices. Moreover, they find that CDS prices lead bond prices for a larger number of firms than the other way around. They also analyze how the relationship between CDS, bonds and stocks depends on credit quality, size of bond issues and geographic location (see Norden and Weber, 2009, for details). Existing literature also investigates relative price discovery between CDS and equity markets, especially in the context of possible insider trading. Acharya and Johnson (2007) find that there is no unconditional information flow of the CDS market innovations to the equity market except for periods associated with greater tendency for insider trading (e.g. before large increases in CDS premia)

\footnotetext{
${ }^{2}$ Analogous changes were later introduced for European obligors, which became known as the CDS Small Bang.
} 
for a sample of US firms between 2001 and 2004. Using more recent data from 2001 until 2008, Qiu and Yu (2012) confirms the findings of Acharya and Johnson (2007) and further demonstrates endogenous information provision by dealer banks during periods when there is larger information flow from the CDS to equity markets, which is before large CDS premia increases. In contrast, Hilscher et al. (2013) find that equity prices lead CDS prices and not the other way around even preceding large increases in CDS premia. However, they do find that CDS prices respond with a lower delay during salient news events (e.g. preceding earnings announcements), which they explain by investor inattention during other periods.

\section{Modeling Approach}

\subsection{CreditGrades}

We use the CreditGrades model, which was developed jointly by RiskMetrics, Deutsche Bank, Goldman Sachs and JP Morgan. This model has become an industry benchmark and it has been widely used by capital structure arbitrageurs according to $\mathrm{Yu}$ (2006) and cited therein Currie and Morris (2002). The advantage of this model is that it provides closed-form formulas for the survival probabilities of obligors and also fair CDS premia levels that are functions of market observables. In this section, we provide the basic overview of the model and provide formulas used in our study, while detailed derivation of the model and its calibration is given in the CreditGrades Technical Document (see CreditGrades, 2002).

CreditGrades belongs to the class of structural models introduced by Black and Scholes (1973) and Merton (1974). According to these models both equity and debt can be viewed as options on the underlying firm value. Default of a firm in structural models occurs when the asset value drops below a predetermined default barrier. Since application of the basic structural models leads to strong underestimation of short-term credit spreads, several approaches were developed to address this issues. A popular approach is to incorporate jumps in the asset value process (e.g. Zhou, 2001) 
or to incorporate endogenous default barrier (e.g. Leland and Toft, 1996). ? $^{3}$ CreditGrades takes a simpler approach by introducing uncertain global recovery rate that is drawn from a lognormal distribution.

CreditGrades posits a stochastic process $V t$ that (intuitively) represents the asset value of the firm. $V t$ is defined as a geometric Brownian motion with zero drift:

$$
\frac{d V_{t}}{V_{t}}=\sigma d W_{t}
$$

where $W$ denotes a standard Brownian motion and $\sigma$ is the asset volatility. The default threshold is assumed to be equal to the recovery given default, which is $L \cdot D$, i.e. the product of the recovery on debt $L$ and the amount of firm's debt $D$.

The (global) recovery rate is assumed to have a lognormal distribution with mean $\bar{L}=\mathbf{E} L$ and standard deviation $\lambda$ such that $\lambda^{2}=\operatorname{Var}(\log (L))$. It is further assumed that $L D=\bar{L} D e^{\lambda Z-\lambda^{2} / 2}$ where $Z$ is the standard normal random variable independent of the asset value process. In this setting, $Z$ is unknown until default occurs, which captures uncertainty about the level of firm's debt implying that a default event can occur unexpectedly.

CreditGrades (2002) gives the formula for the survival probability of an obligor:

$$
P(t)=\Phi\left\{\frac{A_{t}}{2}+\frac{\log (d)}{A_{t}}\right\}-d \cdot \Phi\left\{\frac{A_{t}}{2}-\frac{\log (d)}{A_{t}}\right\}
$$

where $d$ and $A_{t}$ are defined as follows:

$$
\begin{gathered}
d=\frac{S_{0}+\bar{L} D}{\bar{L} D} e^{\lambda^{2}} \\
A_{t}^{2}=\left\{\sigma_{S}^{*} \frac{S^{*}}{S^{*}+\bar{L} D}\right\}^{2} t+\lambda^{2}
\end{gathered}
$$

and all parameters are solely a function of market observables, specifically: $S_{0}$ is the initial stock price, $S^{*}$ is the reference stock price, $\sigma_{S}^{*}$ is the reference stock volatility, $D$ is debt per share, while $\bar{L}$ and $\lambda$ are as defined previously, respectively, mean global debt recovery and its standard

\footnotetext{
${ }^{3}$ See Eom et al. $(2004)$ for a review and comparison of different structural models.
} 
deviation (CreditGrades, 2002).

Given the formula for the survival function, the fair spread on a CDS contract can be obtained by equating the expected value of the default leg with the expected value of the premium leg. After derivations (see CreditGrades, 2002), the fair CDS premia denoted ' $c$ ' can be computed as:

$$
c=r(1-R) \frac{1-P(0)+e^{r \xi}(G(t+\xi)-G(\xi))}{P(0)-P(t) e^{-r t}-e^{r \xi}(G(t+\xi)-G(\xi))}
$$

where $\xi=\lambda^{2} / \sigma^{2}$, and:

$$
G(u)=d^{z+1 / 2} \Phi\left\{-\frac{\log (d)}{\sigma \sqrt{u}}-z \sigma \sqrt{u}\right\}+d^{-z+1 / 2} \Phi\left\{-\frac{\log (d)}{\sigma \sqrt{u}}+z \sigma \sqrt{u}\right\}
$$

where $z=\sqrt{\left(1 / 4+2 r / \sigma^{2}\right)}$.

In the aforementioned formulas, CreditGrades (2002) specifies that the asset volatility $\sigma$ is obtained by rescaling the observable stock return volatility as follows:

$$
\sigma=\sigma_{s} \frac{S}{S+\bar{L} D}
$$

where $\sigma_{S}$ is the stock volatility, $S$ is the stock price and $\bar{L} D$ is as defined previously. Moreover, CreditGrades (2002) suggests using some reference stock price $S^{*}$ and reference volatility $\sigma_{S}^{*}$ in Eq. 7 that is kept stable over a period of time. That is proposed because "for a stable asset volatility, the equity volatility increases with declining stock price, and eventually reaches very high levels for a company at the brink of collapse" (CreditGrades, 2002). The equity volatility $\sigma_{S}^{*}$ is typically computed as a long-term historical volatility based on past stock returns, while option-implied volatility can also be used (CreditGrades, 2002).

Finally, we use the formula derived by $\mathrm{Yu}(2006)$ to compute the CDS-equity hedge ratio $\delta$ at contract inception:

$$
\delta=\frac{1}{r} \frac{\partial c(0, T)}{\partial S}\left\{P(0)-P(T) e^{-r T}-e^{r \xi}[G(T+\xi)-G(T)]\right\} .
$$

\footnotetext{
${ }^{4}$ The equations, definitions and variable names provided in this section are taken directly from CreditGrades (2002).
} 


\subsection{Implementation}

The implementation of CreditGrades is straightforward since all formulas are derived in closed form in terms of market observables. We follow CreditGrades (2002) in setting the mean of the global recovery rate $\bar{L}$ to 0.5 and its standard deviation to 0.3 . These values are estimated in $\mathrm{Hu}$ and Lawrence (2000) based on historical data (i.e "Portfolio Management Data and Standard \& Poor database").

The existing studies on capital structure arbitrage, among others $\mathrm{Yu}$ (2006) and Bajlum and Larsen (2008), use either historical equity volatilities or option-implied volatilities when estimating model CDS premia with CreditGrades. However, if either historical or option-implied volatilities are directly used as inputs to CreditGrades, then the level of the model-derived CDS premia for most companies is very different compared to the actual market CDS premia. In particular, estimated CDS premia are strongly underpredicted by the models during periods of low volatility and especially for companies with low leverage. To circumvent this problem, $\mathrm{Yu}(2006)$ and others fit the mean of the recovery rate $\bar{L}$ for each company to minimize deviations between the model and market spreads over the first 10 days of the sample. This approach ensures that the model and market spreads are at similar levels at the beginning of the sample, but afterwards the model and market premia can diverge and remain at different levels. Persisting deviations between the model and market spreads are problematic and might give rise to spurious arbitrage opportunities if they are a result of a 'structural' change in market or company-specific conditions. For example, a change in leverage of a company might have a dramatic impact on the level of the mean of the recovery rate $\bar{L}$ needed to equate the model and market spreads (given model misspecification). Moreover, the problem with the approach of fitting the sample based on the first 10 days arises if these 10 days are a period of actual mispricing and true arbitrage opportunity. In such a case, according to the methodology of $\mathrm{Yu}$ (2006), a hypothetical arbitrageur would open a new trade on each day when the equity and debt are actually well-aligned. Even worse, it can be that during the first 10 days of the sample, there is an arbitrage opportunity for most companies due to some market-wide event and in such case the results would be strongly biased across the board. Al- 
together, having a careful calibration of the model is particularly important for analyzing trading strategies because persistent 'spurious' trading opportunities might result in taking directional bets on the market (e.g. volatility) that can turn either into losses or profits depending on whether the market moves in one direction or the other. Moreover, the approach used by the aforementioned studies is questionable because they assume that trading strategies have converged when the market CDS premia becomes equal to the model-derived CDS premia, which is likely not to occur if the first 10 days in the sample were a period of even a small arbitrage opportunity.

We take a different approach in calibrating the CreditGrades model to identify mispricing between equity and debt. Our premise is that the market pricing of equity and debt is correct most of the time. We also assume that for mispricing to be exploitable it should be temporary. We therefore obtain the benchmark model-derived CDS premia as follows. First, we compute the market-implied CDS volatility for each day and each company in the sample by finding the level of volatility that when used as an input to CreditGrades produces CDS premium that is equal to the actual market CDS premium. (The other parameters used in CreditGrades, which include debt per share and equity price are taken directly without adjustments.) We will refer to this volatility as 'CDS-implied volatility'. Next, for each company in the sample, we compute a 1-year moving average volatility based on the past CDS-implied volatilities. Finally, we compute the benchmark model-derived CDS premia via CreditGrades using this average volatility. This method of obtaining the benchmark CDS premia has several attractive features. We do not have to calibrate the model based on several days of the data at the beginning of the sample. We simply assume that the 1-year moving average of CDS-implied volatilities is a good estimate for the volatility that gives the fair model-derived CDS price. Such approach detects temporary mispricings and only works if the market in on average correct about CDS pricing. If the CDS market experiences long-term deviations from equilibrium, then our approach will not work, but if that was the case, then also the sense of implementing capital structure arbitrage would be questionable. Finally, we will identify mispricing based on whether there is a substantial deviation between CDS premia obtained from CreditGrades based on the aforementioned 1-year volatility parameter and the market CDS premia. 


\section{Trading strategy}

Devising a successful trading strategy has several key components. One of them is identifying profitable trading opportunities and entering into trades at optimal times. Equally important is identifying when to close down the positions, which can be either when the mispricing has been corrected and profit made or when the position has not converged, but keeping the position open is no longer expected to be profitable. While a number of more sophisticated methods could be used, we follow the existing studies (e.g. Yu, 2006) and use a relatively simple trading rule by comparing the level of market CDS premia with model-derived CDS premia as explained below. We use these simple entry/exit triggers to be consistent with the previous studies and also to mitigate data-snooping concerns. In this section, we also explain how profits on the trading strategies are computed and how we construct the indices capturing gains from capital structure arbitrage.

\subsection{Entry}

We identify arbitrage opportunities by comparing the market CDS premia with the model-derived CDS premia obtained from the CreditGrades model. Let us denote the market CDS premia as $c_{M K T}$ and the fair model-derived premia as $c_{C G D}^{*}$. We identify mispricing when the difference between the market and model premia exceeds a certain (relative) trading trigger denoted by $\alpha$. If the model CDS premia is sufficiently higher than the market spread:

$$
c_{C G D}^{*}>(1+\alpha) c_{M K T}
$$

or equivalently the cost of buying CDS protection is too low relative to equity prices, we should implement a 'long' capital arbitrage trade by buying the undervalued CDS protection and buying equity as a hedge. The amount of equity is determined based on the hedge ratio, which is computed using Eq. 8. Conversely, if market CDS premia exceeds sufficiently the model premia:

$$
c_{M K T}^{*}>(1+\alpha) c_{C G D}
$$


an arbitrageur should implement a 'short' capital arbitrage trade by selling overvalued protection and shorting equity as a hedge. Following the existing literature, we assume static hedging, so the equity positions are not rebalanced once the trade is implemented.

Note that changes in model CDS premia at short horizons are primarily driven by changes in equity prices. That is because debt per share is typically (fairly) constant over short horizons, while our equity volatility estimates used for pricing CDSs are very 'sticky' since they are based on a rolling window of one year. Therefore, the short-term dynamics between model-derived CDS premia and actual CDS market premia is mostly dependent on the changes in equity prices, which is why comparing the model-derived CDS premia with the market CDS premia can be viewed as analyzing mispricing between equity and debt.

While we follow the existing literature in setting the trading trigger based on 'relative' deviation as defined in Eq.9 or Eq. 10, our approach is different in three ways. Firstly, we use a different method to compute the volatility estimate which is obtained as the mean of CreditGrades-implied volatilities averaged over a rolling window of 1 year in the benchmark specification. Secondly, the literature typically assumes the trading trigger $\alpha$ of $50 \%, 100 \%$ or $200 \%$. We choose a trading trigger of $50 \%$ because we use different volatility estimates, which implies that in our study deviations between the model-derived and market CDS premia are smaller. Thirdly, the literature assumes that for a single obligor a new trade is opened on each day when the trading trigger conditions given by Eq. 9 or by Eq. 10 are satisfied, so that there can be multiple trades open for the same company at a given point in time. However, such strategy is not realistic for any hedge fund to follow as it would mean that for some obligors hundreds of trades shall remain opened at the same time, which is not possible given that the typical CDS trade size is $\$ 5$ million. Also, it would imply that a hedge fund would be opening new trades in some cases every day for several months even as the model-derived and market CDS premia continue to diverge further and further away. Such strategy cannot be realistically implemented as it is akin to increasing bets in a casino upon incurring losses. Moreover, following such strategy would bias the sample of implemented trades towards companies for which capital structure arbitrage does not work (i.e. convergence is 
not achieved), while only a small part of all trades would be associated with companies for which prices realign fairly quickly and profits are made. We therefore assume that for a given company, an arbitrage trade is executed only once on the first day when the trading trigger condition is satisfied. Our approach is similar to Gatev et al. (2006) who examine pairs-trading strategies in equity markets. Finally, we assume that if a trade is closed without convergence due to the maximum holding period condition (see below for details) or due to a loss exceeding the pre-specified maximum, then no new trade is opened for a given company until its model-derived and market CDS premia first move back within the convergence threshold.

\subsection{Exit}

The strategy should be closed when the pricing of equity and debt converges. We assume that convergence occurs when the market CDS premia and the (current) model-derived CDS premia move back within a 5\% margin of each other. This is different compared to the existing studies which assume full convergence and close down trades when the model-derived and market CDS premia become equal or cross. Assuming full convergence is problematic as there is likely to be no convergence for many trades when there is even a small model misspecification. Our approach not only assumes a 5\% margin of convergence, but convergence can also occur due to adjustment of volatility estimator that is constructed as a long-term (1 year) moving-average CDS-implied volatility. This means that when an initial deviation persists, then as more and more time passes, we adjust the volatility used for computing model-derived CDS premia to account for the fact that the longer the deviation continues, the more likely it is to be driven by a fundamental change in the relative pricing and the less likely it constitutes a true arbitrage opportunity. Of course in our approach a trade that has converged can in principle be unprofitable, but that is rare and such cases can often be interpreted as a structural change in the relative pricing of equity and debt that has resulted in losses.

If there is no convergence, we assume that trades are closed upon reaching the maximum holding period of 180 days. A similar assumption is made by $\mathrm{Yu}$ (2006) and others. We also assume that a trade is closed down when its loss exceeds a pre-specified maximum drawdown 
threshold. We set the maximum drawdown from a trade to $50 \%$ of the CDS notional bought or sold. While the $50 \%$ drawdown is arguably large, we choose it because we consider a trading trigger of $50 \%$, while other studies also use $100 \%$ or even $200 \%$ trading triggers. We therefore wish to allow the relative pricing between equity and debt to deviate further away from the equilibrium once a trade is executed. Also, a larger drawdown of 50\% limits the data-snooping concerns as we simply accept the losses as they occur. In any case, the results will show that the drawdown of $50 \%$ is very rarely reached.

\subsection{Valuing trades}

The value of an outstanding CDS-equity trade depends on the value of its equity and CDS components. The valuation of the equity position is straightforward and it is derived from the equity price (adjusted for dividends). The valuation of the CDS position is more involved. In our analysis, we only use market quotes for contracts with 5 year maturities because they are the most liquid. We therefore follow the literature (e.g. Yu, 2006) and we approximate the CDS premia on off-the-run contacts with CDS premia on the current 5-year contracts. Given that our positions are on average closed after four months, this approximation is harmless as the CDS curve is fairly flat at such short intervals. While secondary trading in the CDS market is limited, the arbitrageur wishing to close an existing position can in most cases find a dealer to enter a reverse trade. For dealers such off-the-run positions are still manageable as they are almost perfectly hedgeable with on-the-run contracts. For detailed discussion on unwinding CDS transactions we refer to CreditSuisse (2007).

When assessing profitability of capital structure arbitrage, we compute holding period returns on arbitrage trades by assuming that the initial capital is equal to $50 \%$ of the CDS notional traded. Given that a hedge fund enters into multiple trades across different companies, such capital level is by far sufficient to ensure solvency throughout the sample although it might be insufficient for a single trade. The capital is needed for two reasons. The first is implementing the equity hedge, which in our sample is on average 0.22 in absolute terms of the CDS notional traded. This gives \$1.1 million for the standard \$5 million notional CDS trade. Note however that about half of the trades in our sample are 'short trades' when an arbitrageur should short overvalued protection and 
short equity as a hedge. In such cases, the capital needed to implement the equity hedge is only a fraction of the aforementioned 0.22 of the CDS notional, which is determined by the required margin percentage although an arbitgeur might have to replenish the margin account if stock price increases. The second need for the risk capital arises due to CDS collateral posting when the value of the positions change. However, the capital required for this purpose is mitigated when a hedge fund enters into many positions because on some trades the collateral will be received, while only on some trades it will have to be posted. Of course it is possible that the market moves against an arbitrageur on the majority of the CDS positions, but it is likely to be mitigated by the equity hedges. Ultimately, the level of required capital will for a large part depend on the changes in the value of the portfolio of trades. In Section 5, we show that most trades end in profit and that return indices tracking overall profitability of capital structure arbitrage do not experience large drawdowns. Moreover, the assumed level of capital equal to $50 \%$ of the CDS notional traded (i.e. $\$ 2.5$ million for a standard $\$ 5$ million standard trade) is consistent with the existing literature (e.g. Yu, 2006), which assumes either the 50\% capital level or a lower $20 \%$ level. We choose the higher $50 \%$ level also because in practice hedge funds often close when they loose more than $20 \%$ of their total capital (Duarte et al., 2007). Using a lower assumption of 20\% capital, a loss of $20 \%$ of the fund capital would be incurred as soon as the value of the open positions drops by just $4 \%$ compared to the notional of CDS trades, which appears rather risky. While we report the holding period returns for the 50\% assumed capital level, the returns are scalable so simply by multiplying the obtained returns one can compute what the returns would be for other capital levels.

Valuation of trades can be done without transaction costs and with transaction costs. Arbitrage returns without transaction costs would only be attainable to dealers. To account for transaction costs, we use average bid-ask quotes provided by Markit Liquidity Reports as discussed in Section 4. Following the existing literature on capital structure arbitrage, we ignore transaction costs on equities because we only consider large and liquid companies for which equity transaction costs can be assumed to be negligible especially since we use static hedging and trades are only executed to open and close arbitrage positions. 


\section{Data}

The data used in this study is obtained from several sources. The equity price data is taken from CRSP and the balance sheet data comes from Compustat. Data on CDS valuations and CDS liquidity measures is taken from Markit, a leading industry provider of CDS data. Data on CDS trading activity comes from DTCC, a leading provider of clearing, settlement and information services in the CDS market. Interest rates and the VIX index are obtained from the FRED database of the Federal Reserve Bank of St. Louis. Our final dataset is constructed by matching data across the aforementioned datasets resulting in 105,409 observations for a total of 183 companies covering the period from 07-16-2010 to 11-16-2012. The final dataset has a panel structure with each observation corresponding to a unique pair of date and obligor. Detailed descriptions on the data series are given further down in this section.

We filter the data based on several criteria. We exclude companies in the financial and utilities sector because their capital structures are known to pose challenges in modeling using the structural models. Similar approach is taken in most studies on capital structure arbitrage (e.g. Yu, 2006) or calibrating structural models to market data (e.g. Cao et al. 2011). Further, we select companies for which the CDS markets are large enough to ensure fairly continuous series of data in our sample period (coverage at $95 \%$ of dates). This biases our sample towards the more liquid part of the CDS market, but it ensures that we only consider companies that have observable and tradable CDS quotes and for which potential mispricing can be exploited by arbitrageurs.

\subsection{Markit}

Markit provides composite prices for credit default swaps (thereafter 'CDS premia') that are produced daily based on valuations submitted by a number of contributing financial institutions, which includes leading dealer banks in the CDS market. The quotes received by Markit are processed to ensure high quality and consistency. This includes tests on whether CDS premia satisfy logical conditions that should hold between CDS contracts on the same name reference entitiy along the maturity curve and across different restructuring clauses. Markit also removes outliers and stale 
prices. For a composite price to be provided there must be at least three contributing banks of which at least two pass the aforementioned tests. For details on the procedure see Markit (2011).

The CDS premia are provided by Markit separately for each variant of maturity, underlying debt seniority, restructuring and currency. We choose the 5-year CDS contracts on senior unsecured debt because they are the most liquid. Our sample comprises of companies quoted on North American exchanges, which includes some cross-listed companies domiciled in Europe. Therefore we are careful to choose the most liquid variant of the restructuring clause. For North-American domiciled companies that is 'no restructuring', while for European companies it is 'modifiedmodified restructuring'. We also select CDSs denominated in the currency corresponding to the most liquid variant, which is either USD or EUR depending on the domicile region.

Since CDS contracts are typically quoted as a combination of upfront payments and running spreads (i.e. coupons), the quotes are converted by Markit into the running spread only pricing convention. This ensures comparability of the pricing data and it is done because coupons can be very different depending on whether a name is high-yield or investment-grade. Moreover, different standard coupons are used in North America and Europe. The details on the ISDA model used for conversion between upfront payments and running spreads can be found in ISDA (2012).

Markit also provides Liquidity Reports, which contain daily averages of CDS bid-ask spreads received by the buy-side clients for a large number of liquid obligors. Markit extracts this data from electronic messages sent by dealers to buy-side clients (so called 'dealer runs'). The bid-ask spread is then converted by Markit to the running spread convention. The reported bid-ask spreads are actual observed bid-ask spreads when quotes are available from at least two dealers. In other cases, Markit estimates the bid-ask spreads based on past bid-ask spreads for a given company and also based on bid-ask spreads of companies with a similar number of pricing submissions (see Markit, 2012, for details).

Markit also produces a 'Liquidity Score' that summarizes different aspects of liquidity into one measure. The liquidity score is computed based on the level of bid-ask spreads relative to the mid-quote, market depth measured by the number of dealers and staleness of prices supplied 
by dealers. These variables are appropriately transformed by Markit into a single liquidity score taking an integer value between 1 and 5 with 1 representing the most liquid obligors. For details on the liquidity score we refer to Markit (2012).

\subsection{CRSP}

The equity price data comes from CRSP. The equity prices are adjusted for splits and they are computed as the averages of the closing bid and ask quotes. CRSP also provides holding period returns, which account for dividends and splits. From CRSP, we also take stock dividend payouts.

\subsection{Compustat}

The debt outstanding is taken from Compustat. It is computed as the sum of the total long-term debt (Compustat's field 'DLTTQ') and debt in current liabilities ('DLCQ'). From Compustat, we also take the number of shares outstanding to compute debt per share.

\subsection{DTCC}

The Depository Trust \& Clearing Corporation (DTCC) provides weekly data on CDS notionals outstanding and risk transfer activities. As described previously in Wojtowicz (2013): "DTCC operates the Trade Information Warehouse that collects data from all major CDS dealers and covers almost the entire market. DTCC releases weekly data reports covering 1,000 companies with the highest notional outstanding in any given week. The data is publicly available on the DTCC's website. We take the net outstanding notionals for single-name corporates (Table 6 of DTCC data). We also take the volume of weekly risk transfer transactions (Table IVa of DTCC data). The risk transfer activity captures mostly new CDS trades and CDS terminations, while it excludes transactions not resulting in risk transfer such as those related to trade compressions." 


\subsection{FRED}

The FRED database of St Louis's FED provides the TED spread and the VIX index 5 ,

\section{Empirical Analysis}

We analyze risks and returns of capital structure arbitrage from several perspectives. We first report statistics showing the number of trades and the reasons for subsequent closing of the trades (e.g. convergence of spread) and we also report holding period returns. To gain insight into what drives profitability and risks of the strategies, we analyze the aforementioned results within subsamples based on various characteristics of obligors such as rating, liquidity measure, level of premia and trading volume, which has not been done in the previous studies except for the rating subsamples. When analyzing strategies within subsamples we assume that a trade is classified into a given subsample based on the value of a given characteristic on the starting day of the trade, which of course can change subsequently. In the next stage, we look at the returns of indices tracking the performance of a portfolio of trades assuming that a fund enters into each trading opportunity. We thus analyze the performance of capital structure arbitrage along the time dimension and we focus both on when trading opportunities arise and also their profitability. Finally, we analyze whether returns on a portfolio of trades can be explained by common risk factors.

Unless stated otherwise, we report the results of capital arbitrage strategies implemented using the baseline specifications with a trading trigger $\alpha$ of 0.5 and maximum holding period of 6 months. The volatility used for calculating model-derived CDS premia is based on a 1-year moving average of CDS-implied volatilities. An arbitrage trade is closed down when convergence is achieved, the maximum drawdown of $50 \%$ is exceeded or upon reaching the maximum holding period.

\footnotetext{
${ }^{5}$ According to CBOE (2009), "VIX measures 30-day expected volatility of the S\&P 500 Index. The components of VIX are near- and next-term put and call options, usually in the first and second SPX (S\&P 500 index) contract months. 'Near-term' options must have at least one week to expiration; a requirement intended to minimize pricing anomalies that might occur close to expiration. When the near-term options have less than a week to expiration, VIX 'rolls' to the second and third SPX contract months. For example, on the second Friday in June, VIX would be calculated using SPX options expiring in June and July. On the following Monday, July would replace June as the 'near-term' and August would replace July as the 'next-term'." The precise formula for the VIX index is given in CBOE (2009).
} 


\subsection{Returns of individual arbitrage trades}

Table 1 presents the results obtained under the baseline specifications. The table reports the statistics for the entire sample and within three rating groups, respectively, AA-AAA, A, BB-BBB and B-CC. We use data from Markit that reports the average rating from S\&P and Moody's. In column (1) of Table 1 we report the composition of our sample split by ratings. We can see that $58.62 \%$ of the observations have a rating of either $\mathrm{BB}$ or $\mathrm{BBB}$, while $32.49 \%$ have an A rating. The highest AA-AAA rated category and the lowest B-CC rated category are less frequent and in total they add up to less than $10 \%$ of the sample.

Let us first discuss the results for the full sample in the first row of Table 1 . In column (2) we can see that the mean holding period is about 81 working days. Column (3) reports that there were 308 arbitrage trades executed during the sample period. Since the total number of companies in the sample is 183 , we had on average around 1.7 trades per company, which means that the mispricings between model-derived and market CDS premia are not unusual. In column (4), we can see that 180 of the trades converged, i.e. the model-derived and market CDS premia moved back to equilibrium. This is a bit below $60 \%$ of all trades, which is much larger compared to the study of $\mathrm{Yu}$ (2006) in which only 372 trades converged out of 57,621 trades in total. Note that the number of trades is much larger in $\mathrm{Yu}(2006)$ because he uses different trading strategies and opens multiple trades for one company. In column (4) we can see that dradowns, i.e. situations when losses from a trade exceed $50 \%$ of the CDS notional, are very rare. This is consistent with $\mathrm{Yu}(2006)$ who obtained only 70 drawdowns out of 57,621 trades. In column (6) we can see that 88 trades are closed because there is no convergence within 6 months. Finally, in column (7) we can see that 39 trades were still open when the sample ends.

Analyzing the results on holding period returns (without transaction costs) reported in columns (8)-(12), we can see in column (8) that the mean holding period return is $7.47 \%$. This is a return

computed based on the initial level of capital of $50 \%$ of the CDS notional. Analogous result of $\mathrm{Yu}(2006)$ is $0.84 \%$ for the investment grade companies and $2.78 \%$ for the speculative grade com- 
panies. Next, we can observe that the range of the returns is from $-109.80 \%$ to $336.47 \%$ with a standard deviation of $35.82 \% .^{6}$ The standard deviation is large compared to the mean holding period return implying that the mean return from the strategy can be substantially driven by outliers. In other words, the overall profitability of capital structure arbitrage is largely dependent on infrequent but large profits. Nevertheless, as many as 202 trades out of the total of 308 are profitable (over 65\%) showing that most trades result in gains. Capital structure arbitrage is therefore not about 'picking up nickels in front of a steamroller' as also found by Duarte et al. (2007).

The results within the rating category subsamples reported in the following rows reveal several patterns. First, the mean holding period returns are higher the lower the credit ratings with the mean return on AA-AAA companies equal to $0.74 \%$ and as much as $42.99 \%$ for the CC-B companies. However, the results for AA-AAA and CC-B categories have to be interpreted with caution as they represent only about $9 \%$ of the sample. We also find that the mean return on A rated companies is $0.95 \%$, while for $\mathrm{BB}-\mathrm{BBB}$ rated companies it is $10.22 \%$. Second, we can see that trades are implemented across all rating categories although more trades occur in the A rated category followed by the BB-BBB category if we relate the number of trades to the number of observations in each group. Third, the standard deviations of the returns are higher the lower the rating category. It shows a clear trade-off between risks and returns of capital structure arbitrage with trades in the lower rated categories having higher returns, but also higher risks.

As for interpretation of the results, the reported holding period returns constitute relatively large gains when considering the rather short mean holding period of less than four months during which the capital is engaged. For example, the mean holding period return of $7.47 \%$ without transaction costs translates into $24.35 \%$ annualized return. Moreover, this return could be even higher had we chosen a lower initial level of capital for each trade. Assuming an initial level of capital of $20 \%$ of the CDS notional instead of $50 \%$ would make the annualized return increase to as much as $60.875 \%$. An arbitrageur could also choose a different maximum drawdown level from a strategy and close trades when a loss exceeds, for example, $40 \%$ or $30 \%$ of the CDS notional traded

\footnotetext{
${ }^{6}$ The minimum return of $-109.80 \%$ is a result of a jump, which subsequently triggers closing of a trade due to the maximum drawdown condition.
} 
instead of $50 \%$ threshold assumed in our baseline specifications. When assuming $40 \%$ maximum drawdown, the mean holding period return is slightly higher at $7.55 \%$ instead of $7.47 \%$, while for a $30 \%$ maximum drawdown the mean holding period return decreases to $6.71 \%$. This suggests that a number of trades incur substantial losses exceeding $30 \%$ before eventually turning profitable. However, we show in the next subsection that these losses occur idiosyncratically and do not require large capital at a portfolio level. Looking at the returns across the rating categories, it is not surprising that capital structure arbitrage provides relatively low returns for AA-AAA rated obligors since they have fairly low CDS premia, which are largely driven by overall market conditions and not company-specific credit factors. It is also likely to be difficult to hedge CDS positions in this subsample with equity positions since CDSs on highly rated companies are similar to very deep out of the money options. Next, it is interesting that for the A rated companies the mean holding period return is very limited at $0.95 \%$, while the overall success of capital structure arbitrage is due to the BB-BBB rated category, which covers $58.62 \%$ of the sample and shows a large mean return of $10.22 \%$. The $\mathrm{BB}-\mathrm{BBB}$ rated companies are known as the cross-over companies being at the investment grade threshold and depending on the circumstances they are likely to either fall into junk categories or improve and perform robustly. Our results suggest that equity and bond investors often hold diverging views about the prospects of such companies and that these views tend to realign subsequently leading to large profits for capital structure arbitragers. Finally, the lowest rated group of CC-B obligors has the highest mean return of $42.99 \%$, but it only provides 9 arbitrage trade opportunities.

The results presented in columns (8)-(10) are computed without accounting for transaction costs, so such arbitrage opportunities would only be attainable to dealers. We account for transaction costs in columns (11)-(15) and we can see that all trading strategies are still profitable while the holding periods returns decline by between $0.5 \%$ to $1.5 \%$. In column (15) we report average CDS bid-ask spreads across rating groups and we can see that they range from $5.59 \%$ to $12.28 \%$. These bid-ask spreads are expressed as a percentage of the bid-ask spread quoted in the coupon only ('running spread') convention relative to the CDS premia also quoted in the coupon only con- 
vention. The reported bid-ask spreads are based on actual bid-ask quotes collected by Markit. It turns out that CDS bid-ask spreads are substantially larger than the 5\% bid-ask spread assumed in the existing literature on capital structure arbitrage (see $\mathrm{Yu}, 2006$, among others). Moreover, $\mathrm{Yu}$ (2006) analyzed the time period between 2001 and 2004 when the CDS market was far less liquid than in 2010-2012 analyzed in our study, which means that their assumption on bid-ask spreads was likely far too optimistic.

In Table 2 we analyze capital structure arbitrage within subsamples defined based on the level of CDS premia. The first row shows the results for the full sample, so it is the same as the first row of Table 2. Next, we split the sample by CDS premia such that the first group corresponds to CDS premia levels below 100 bps and it contains $50.11 \%$ of sample observations, the second group has CDS premia between 100 bps and 200 bps and contains $32.41 \%$ of the observations, while the third group has CDS premia levels above 200 bps and covers $17.48 \%$ of the sample. By comparing columns (1) and (3) we can infer that, relative to the number of observations in each of the groups, the trades occur with almost the same frequency across these groups. In columns (8)-(12), we can see that mean holding period returns are $0.87 \%, 2.66 \%$ and $37.24 \%$, respectively, for the three subsamples with the highest return corresponding to the group with CDS premia above 200 bps. It implies that the mean holding period return of $7.47 \%$ in the whole sample is primarily driven by the high mean return in the group with CDS premia above 200 bps even though this group contains only 51 trades out of a total of 308 trades. We can also observe that standard deviations of the holding period returns reported in column (11) are higher the higher the CDS premia of a subsample. Nevertheless, in the subsample with CDS premia above $200 \mathrm{bps}$, more than $80 \%$ of trades end up in profit (see column (12)), while only about $62 \%$ of trades end up in profit for the other two subsamples. This indicates that in our sample executing capital structure arbitrage trades on the most risky obligors provides a very attractive trade-off between risks and returns. Inclusion of transaction costs in columns (13)-(17) has little impact on the aforementioned relationships. We can see that transaction costs reduce a much larger share of the returns in the subsample with CDS premia below $100 \mathrm{bps}$ and between 100 and $200 \mathrm{bps}$ than for the subsample with CDS premia of 
200 bps or more.

Profitability of capital structure arbitrage can have several sources. It might be attributable to actual mispricing between equity and debt, which arises because these markets are not perfectly integrated as different types of investors are active in each. Another explanation for a relative mispricing between equity and debt might be different speeds of price discovery in both markets that is demonstrated by Blanco et al. (2005), Acharya and Johnson (2007) and Hilscher et al. (2013) among others. However, the assumed threshold defining tradable mispricing between model-derived and market CDS premia is rather high at 50\%, which makes this explanation unlikely. Moreover, the holding periods are about 80 working days on average, which makes the speed of price discovery an unlikely explanation for arbitrage profits. Yet another explanation for profitability of capital structure arbitrage is that in practice it would be limited by liquidity considerations. While we include bid-ask spreads in the previous results, there are other aspects of liquidity such as market depth and price-staleness. We therefore investigate the relation between broadly understood liquidity and capital structure arbitrage returns in Tables 3, 4 and 5

In Table 3 we analyze returns on capital structure arbitrage within subsamples based on Markit's liquidity scores. The liquidity score incorporates different aspects of liquidity and it is based on the level of bid-ask spread relative to the mid-quote, market depth (number of dealers) and staleness of prices supplied by dealers. In column (8) of Table 3 we can see that the highest mean holding period return of $8.90 \%$ is obtained for the most liquid obligors with a liquidity score of 1 , followed by a return of $6.29 \%$ for obligors with a liquidity score of 2 . The lowest mean return of $1.82 \%$ is obtained for a group of illiquid companies with Markit's score of 3 or more. These results clearly demonstrate that low liquidity is not an explanation for capital structure arbitrage profits, but actually it seems to reduce arbitrage profitability. Moreover, the result that highest arbitrage profits are attainable in the most liquid group with a liquidity score of 1 , which also covers $60.21 \%$ of our sample, further suggests that capital structure arbitrage opportunities can be exploited by investors. When incorporating transaction costs, the relative profitability of the more liquid obligors becomes even more apparent as they have relatively low bid-ask spreads. 
Another aspect that we investigate is whether capital structure arbitrage returns are associated with the volume of trades. For this purpose, we use average weekly volume of CDS trades per obligor to construct three groups of obligors with weekly trading volume of $\$ 50 \mathrm{M}$ or less, between $\$ 50 \mathrm{M}$ and $\$ 100 \mathrm{M}$, and finally $\$ 100 \mathrm{M}$ or more. One could expect that the integration between equity and CDS prices would be lower for companies with less trading in the CDS market because smaller CDS markets are most likely relatively less efficient, which should give rise to larger arbitrage profits. However, the results reported in Table 4 show that this is not the case. The mean holding period returns reported in column (8) are 3.87\%, 8.09\% and $11.13 \%$, respectively, in the aforementioned groups with the highest return obtained for the most traded companies with a weekly volume of $\$ 150 \mathrm{M}$ or more. This suggests that profitability of arbitrage trades is not associated with limited volume of trades. The finding that the highest profits are obtained for companies with large CDS trading volumes indicates that the reported arbitrage profits are due to exploitable mispricing between equity and debt. Finally, in Table 5 we further analyze the relationship between capital structure arbitrage and the size of the CDS markets (i.e. net notional outstanding) on individual reference entities. While it is expected that arbitrage profits are higher for smaller CDS markets because such markets are likely to be less efficient, we do not confirm such relationship. The mean holding period returns reported in column (8) are highest for companies with the largest CDS markets exceeding $\$ 1.4$ billion of net notional outstanding, while they are the lowest for the medium-sized CDS markets between $\$ 700$ million and $\$ 1.4$ billion. Altogether, the results of Table 4 and Table 5 demonstrate that capital structure arbitrage profits are not explained by possibly lower CDS price discovery for reference entities that have CDS markets that are smaller in size or have lower trading volume.

\subsection{Aggregate returns along the time dimension}

In the previous subsection, we have analyzed returns on capital structure arbitrage across various subsamples related to obligor characteristics. Another important aspect of the risk-return properties of capital structure arbitrage is its time-series dimension. Analyzing this dimension will shed light on whether profitability of capital structure arbitrage is limited to specific time periods or 
events. After preliminary graphical analysis, we will construct return indices tracking profitability of capital structure arbitrage and we will also analyze whether they can be explained by standard risk factors.

We start by presenting the behavior of the number of trades executed until a given date in Panel A of Figure 1. We can immediately observe that new trades are started fairly evenly over time since the cumulative number of trades opened until a given date is almost a straight line. This means that deviations between model-derived CDS premia and market CDS premia arise at a fairly constant frequency despite varying credit conditions, which suggests that such deviations are attributable to company-specific factors rather than some common economic factors or market-wide events. However, in Panel B of Figure 1 we present the number of arbitrage trades opened on any given date and we observe that there is an accumulation of open trades between September 2010 and January 2011 during which period the number of open trades reaches a peak of 69. This result indicates that during this period very few existing trades are closed down, while the number of new trades being opened remains fairly constant as seen in Panel A. During the rest of the sample period, the number of trades oscillates at a level of slightly below 40 .

In Figure 2 we analyze the profits earned on implementing the capital structure arbitrage strategy. Panel A depicts the behavior of retained profits earned by executing each arbitrage trade opportunity with $\$ 5$ million CDS notional and an appropriate equity hedge position. Panel B shows the sum of these retained profits and the value of currently opened positions, which reflects the full profit or loss obtained from executing the strategy until a given date. We can see that the total profit reaches almost $\$ 60.0$ million dollars by the end of our sample period. This gives roughly $\$ 195 \mathrm{~K}$ per trade given that 308 trades were executed in total, which is an attractive return assuming an initial capital of $\$ 2.5$ million and an average holding period of around 81 days. However, we can see that most of these profits are attained in a period from the start of September 2010 to the second week of January 2011 when the cumulative profits from the strategy increase from a slightly negative level to over $\$ 40$ millions. This represents almost $70 \%$ of the total profit made throughout the sample period, while it is earned during less than 5 months out of a total of 28 months in the 
sample period. This is an important finding because it shows additional risk-return property of capital structure arbitrage strategy that is not seen from the analysis of Tables 1-6 and it is also not discussed in the previous studies of $\mathrm{Yu}(2006)$ and others.

Concentration of profits within a period of a few months poses a challenge for implementing capital structure arbitrage. A financial institution active in this arbitrage strategy must allocate sufficient capital and divide it among possible arbitrage trade opportunities as they appear. As shown in Panel B of Figure 1, the number of open trades is at most times around 40, while a peak is close to 70 . An arbitrageur wishing to enter into each trade with an initial capital of $\$ 2.5$ million would have to have available $\$ 172.5$ million dollars at the peak, while most of the time only $\$ 100$ millions would be required. Moreover, we can see in Figure 2 that the time period when the capital need is the highest is exactly the period when the strategy is most profitable (i.e. between September 2010 and January 2011). This might be no coincidence and is perhaps related to some market-wide imbalances. It can also be a demonstration of arbitrageurs' capital constraints who normally trade to realign the prices whenever profitable mispricing between equity and debt arises; however, there can be periods when they reach capital limits and as a result prices diverge further away from the equilibrium leading to large arbitrage profits.

The aforementioned analysis demonstrates that managing and allocating capital between individual arbitrage opportunities is critical and that capital constraints can substantially lower the achievable returns. That is because fully implementing the strategy as proposed in this paper and the previous studies requires maintaining excess capital that can be assumed to earn the risk-free rate. Another problem is that an arbitrageur cannot predict ex-ante what level of capital will be required. Our results clearly demonstrate that an arbitrageur with e.g. $\$ 100$ million capital would not be able to enter into new trades during the time period when most profits were made. In practice the issue of managing capital and deciding on how to execute trades has many dimensions. A fund can lower its typical capital reserve per trade during periods of more trading opportunities or it can borrow new funds etc. In any case, our analysis highlights this dimension of the risks and returns of capital structure arbitrage, which has not been considered by earlier studies. Our 
results indicate that clustering of profitable trades and the associated issue of capital allocation can constitute a 'limit to arbitrage'.

To further illustrate the time-series dimension of the risks and returns of capital structure arbitrage, in Panel A of Figure 3 we show the value of all open trades throughout the sample period, while in Panel B we show the average percentage profit per open trade relative to the initial capital assumed in our study. It becomes immediately clear that most profits are made during the period from September 2010 to January 2011, while much less value is created afterwards for over 1.5 years. In relative terms, in Panel B we can see that in early January 2011 the percentage profit on open trades reaches a peak of almost $22 \%$ compared to the initial capital invested. Coupled with the fact that more trades are opened during this period, we again see that this period drives the overall profitability of capital structure arbitrage in our sample. We can also see in Panel B that the portfolio of trades does not incur substantial losses at any time. To be specific, the loss on open positions never exceeds $3.5 \%$ relative to the initial capital, which suggests that at least in our sample period a fund could use much lower reserve capital and still maintain solvency.

Another perspective on capital structure arbitrage can be gained by analyzing return indices tracking its profitability. We construct such indices in two ways. In the first approach, we start by adding the value of the capital invested and the value of all open positions for each day in the sample. Then, we compute daily returns using these values and in doing so we are careful to account for the changing number of trades and appropriately adjust the reference capital invested on any given day. Finally, we aggregate these daily returns into a weekly return. Such constructed capital structure arbitrage index in presented in Panel A of Figure 4. A second approach to constructing return index is taken from the existing studies on capital structure arbitrage. They assume that every day an arbitrageur makes an equal investment into each open trade. This is equivalent to rebalancing the weights every day such that positions in trades that made gains are reduced, while new capital is put to increase the size of trades that made losses. A daily average return across all open trades is then compounded into a weekly frequency. This return index is shown in Panel B of Figure 4 
Figure 4 shows that weekly return indices predominantly oscillate around zero. The period from September 2010 to January 2011 shows more positive values for both indices. Throughout the sample we can see occasional spikes in the weekly returns with the largest one in Panel A of around -10\% in December 2010 and the largest one in Panel B of around 17\% in April 2010. This shows that substantial changes in the values of the positions can occur on a weekly basis. We also computed the mean and standard deviations of the two return indices. For the return index in Panel A, the mean is slightly negative at $-0.014 \%$ and the standard deviation equals $1.80 \%$, while for the return index in Panel B the mean is $0.47 \%$ with a standard deviation of $2.07 \%$. The negative mean of the first return index is due to the fact that relatively large weekly profits are obtained during the period when many trades are open, while losses are incurred during periods when less capital is invested. The mean of the second return index is $0.47 \%$, but almost $0.14 \%$ of this mean return is due to an outlier weekly return of $17 \%$. For the return index in Panel A, the main problem is that it does not account for the total capital invested. The mean of the first return index is slightly negative and it strongly underestimates the profitability of capital structure arbitrage, which has the mean annualized holding period return on individual trades of around $24.35 \%$. The return index in Panel B has a higher mean, but this index assumes rebalancing of trades every day to have equal weights. From the practical side, a financial institution would be unable to replicate such return index because it would require trading in CDSs on every day, which would by far reduce any profits to below zero. While such approach is used in the existing papers, we note that it does not provide a realistic estimate of attainable arbitrage profits.

Nevertheless, the return index series can shed light on whether profitability of capital structure arbitrage is related to systematic risk factors. Following $\mathrm{Yu}(2006)$ and others, we use equity and bond indices to proxy for equity market risks and bond market risks. Specifically, we use the S\&P 500 returns and the Bank of America Merill Lynch's indices for BBB rated bonds and BB rated bonds to proxy for investment grade and speculative grade bond market risks. In Table 6, we regress weekly return indices in specifications of both Panel A and Panel B of Figure 4, denoted respectively 'Index A' and 'Index B', on several common risk factors. In column (1) we can see 
that the coefficients on S\&P 500 returns as well as BB and BBB bond indices are all significant at the $10 \%$ level, while the coefficient on S\&P 500 is also significant at the $1 \%$ level. This regression is done for the return 'Index A' of Panel A computed without rebalancing of weights. The results indicate that capital structure arbitrage is partly explained by common risk factors, which is in contrast to the findings of $\mathrm{Yu}$ (2006). The R-squared of the regression in column (1) is 15\%, which shows that a sizable part of the returns is explained. In column (2), we repeat the regression using the return index shown earlier in Panel B of Figure 4, which assumes equal investments into each open trade on every day. We can see that while the coefficient on the S\&P 500 return index is still significant, the coefficients on the bond indices become insignificant, and the R-squared of the regression drops to $8 \%$. This highlights important differences between the two methods of computing return indices. Existing studies have used index specification shown in Panel B and found no relation to common risk factors, while for this index we do find a significant relation to the S\&P 500 returns although not the bond factors.

In columns (3) and (4) of Table 6 we extend our analysis of the drivers of the return indices to investigate if profits are related to the TED spread and the VIX index. One could expect that during periods of increased dealer funding costs (TED spread) or increased market volatility (VIX index), the pricing of equity and debt would be more likely to diverge away from equilibrium leading to losses on open arbitrage trades. However, we do not find any significant relationship between capital structure arbitrage return indices and the aforementioned variables.

\section{Conclusions}

In this paper we examine risks and returns of capital structure arbitrage. We demonstrate that capital structure arbitrage offers an attractive mean holding period return of $7.47 \%$, which is $24.35 \%$ on annualized basis. We show that almost $60 \%$ of all trades end in convergence and over $65 \%$ of trades result in profits. Examining the results within different subsamples, we find that returns are relatively higher for lower rated companies and companies with CDS premia above $200 \mathrm{bps}$. We 
also find that the mean holding period return after transaction costs is still large at $6.59 \%$. We then investigate whether such high profitability can be explained by the fact that in practice it would not be exploitable due to low liquidity in terms of market depth. However, we demonstrate that this is not the case since arbitrage profits are even higher for more liquid CDS obligors and obligors with higher CDS trading volume or higher CDS net notional outstanding. We also construct return indices tracking profitability of capital structure arbitrage and we show that at most $15 \%$ of profitability can be explained by common risk factors associated with the stock market (S\&P index) or bond market (Bank of America Merill Lynch's indices for ratings of BB and BBB). It therefore appears that the reported arbitrage returns are exploitable and highly profitable even after accounting for transaction costs computed based on actual bid-ask offers received by the buy-side clients and provided by Markit.

The apparent profitability of capital structure arbitrage has an important limitation that becomes clear when analyzing arbitrage returns in the time-dimension. We show that there is a period of about 4.5 months in our data period of 29 months when the number of open trades more than doubles compared to the average level. This means that an arbitrageur wishing to enter into each trade to replicate the returns reported in this paper would have to keep much excess capital at other times or be able to very quickly raise new capital or increase leverage. Moreover, we show that almost $70 \%$ of the total profits are earned during the aforementioned period of about 4.5 months when the number of open trades and thus the capital needed was much higher than on average. This suggests that such mispricing between equity and debt could be a one-time event or some market imbalance that took time to be corrected by arbitrageurs due to their limited capital. When considering market efficiency, it must be emphasized that in this paper we employ a very simple trading strategy and most likely higher returns would be achievable for more sophisticated strategies perhaps in combination with fundamental analysis. Also on the positive side, our results demonstrate that an arbitrageur investing in each trade would not incur substantial losses on the portfolio of trades during our sample period with the maximum loss being well below 5\%. This suggests that leverage of the arbitrage strategy could be higher than the assumed $50 \%$ or that the leverage of the strategy 
could be increased when the number of open trades clusters. 


\section{References}

Acharya, V. V. and T. C. Johnson (2007). Insider trading in credit derivatives. Journal of Financial Economics 84(1), 110-141.

Bajlum, C. and P. T. Larsen (2008). Capital structure arbitrage: Model choice and volatility calibration. Working paper. Copenhagen Business School and Denmarks National Bank.

Black, F. and M. Scholes (1973). The pricing of options and corporate liabilities. The Journal of Political Economy, 637-654.

Blanco, R., S. Brennan, and I. W. Marsh (2005). An empirical analysis of the dynamic relation between investment-grade bonds and credit default swaps. The Journal of Finance 60(5), 22552281.

Cao, C., F. Yu, and Z. Zhong (2011). Pricing credit default swaps with option-implied volatility. Financial Analysts Journal 67(4), 67-76.

CBOE (2009). The CBOE volatility index - VIX. Chicago Board Options Exchange.

Chen, K., M. Fleming, J. Jackson, A. Li, and A. Sarkar (2011). An analysis of CDS transactions: Implications for public reporting. Staff Report No. 517, Federal Reserve Bank of New York.

CreditGrades (2002). CreditGrades Technical Document. Riskmetrics Group. May.

CreditSuisse (2007). Credit derivatives handbook. Fixed Income Research.

Cserna, B. and B. Imbierowicz (2008). How efficient are credit default swap markets? An empirical study of capital structure arbitrage based on structural pricing models. Working paper. RuprechtKarls University Heidelberg and Goethe University Frankfurt.

Currie, A. and J. Morris (2002). And now for capital structure arbitrage. Euromoney. December.

Duarte, J., F. A. Longstaff, and F. Yu (2007). Risk and return in fixed-income arbitrage: Nickels in front of a steamroller? Review of Financial Studies 20(3), 769-811. 
Eom, Y. H., J. Helwege, and J.-Z. Huang (2004). Structural models of corporate bond pricing: An empirical analysis. Review of Financial Studies 17(2), 499-544.

Gatev, E., W. N. Goetzmann, and K. G. Rouwenhorst (2006). Pairs trading: Performance of a relative-value arbitrage rule. Review of Financial Studies 19(3), 797-827.

Hilscher, J., J. M. Pollet, and M. Wilson (2013). Are credit default swaps a sideshow? Evidence that information flows from equity to CDS markets. Journal of Financial and Quantitative Analysis. Forthcoming.

Hogan, S., R. Jarrow, M. Teo, and M. Warachka (2004). Testing market efficiency using statistical arbitrage with applications to momentum and value strategies. Journal of Financial Economics 73(3), 525-565.

Hu, H. and L. Lawrence (2000). Estimating recovery rates. Internal document. JPMorgan.

ISDA (2012). Standard CDS examples: Supporting document for the implementation of the ISDA CDS standard model. October.

Leland, H. E. and K. B. Toft (1996). Optimal capital structure, endogenous bankruptcy, and the term structure of credit spreads. The Journal of Finance 51(3), 987-1019.

Markit (2011). Documentation: CDS data cleaning process. November.

Markit (2012). Documentation: CDS liquidity user guide. February.

Merton, R. C. (1974). On the pricing of corporate debt: The risk structure of interest rates. The Journal of Finance 29(2), 449-470.

Norden, L. and M. Weber (2009). The co-movement of credit default swap, bond and stock markets: An empirical analysis. European Financial Management 15(3), 529-562.

Qiu, J. and F. Yu (2012). Endogenous liquidity in credit derivatives. Journal of Financial Economics 103(3), 611-631. 
Wojtowicz, M. (2013). The determinants of CDS bid-ask spreads. VU University Amsterdam and Tinbergen Institute.

Yu, F. (2006). How profitable is capital structure arbitrage? Financial Analyst Journal 62(5), $47-62$.

Zhou, C. (2001). The term structure of credit spreads with jump risk. Journal of Banking $\mathcal{E}$ Finance 25(11), 2015-2040. 
Tables 


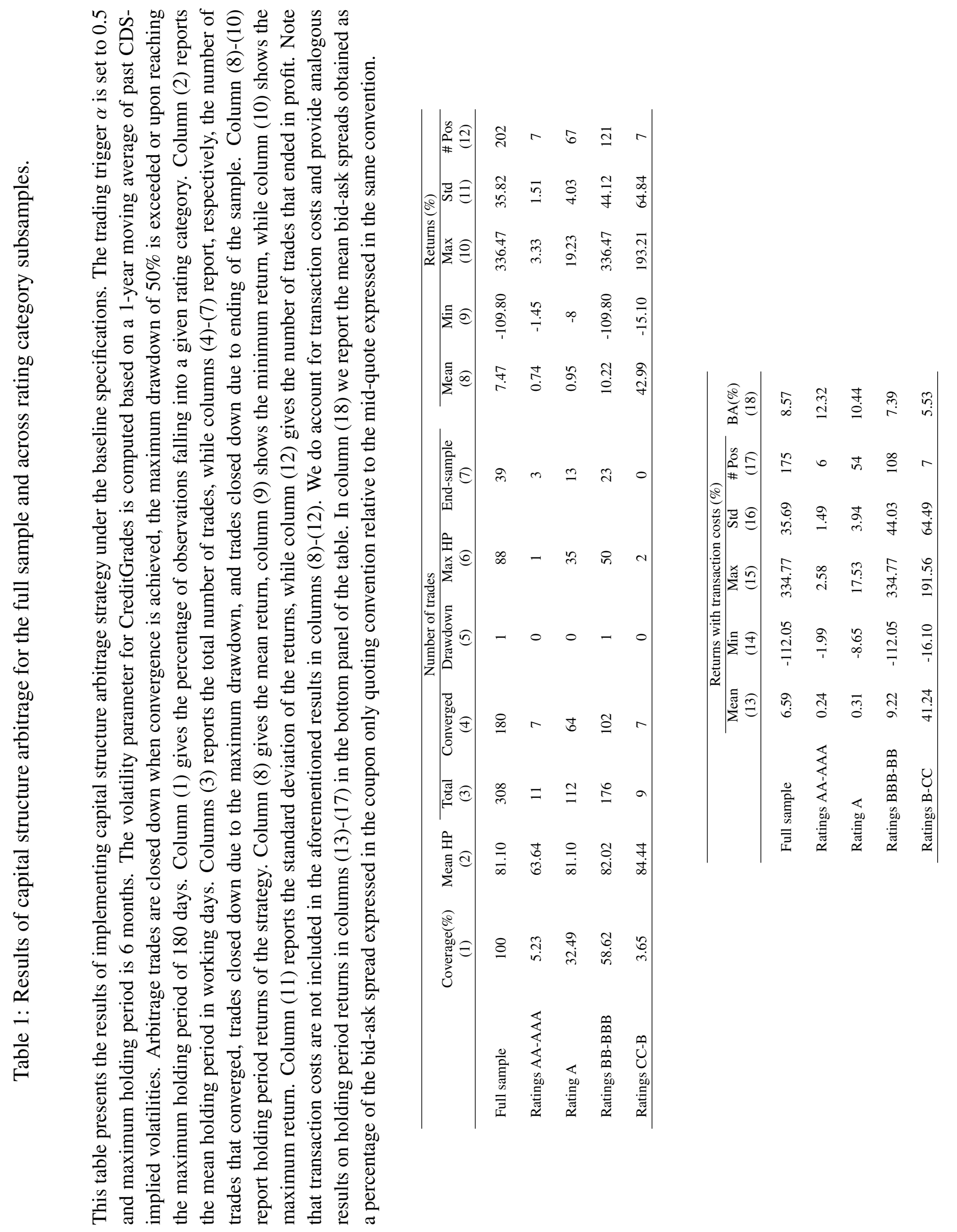




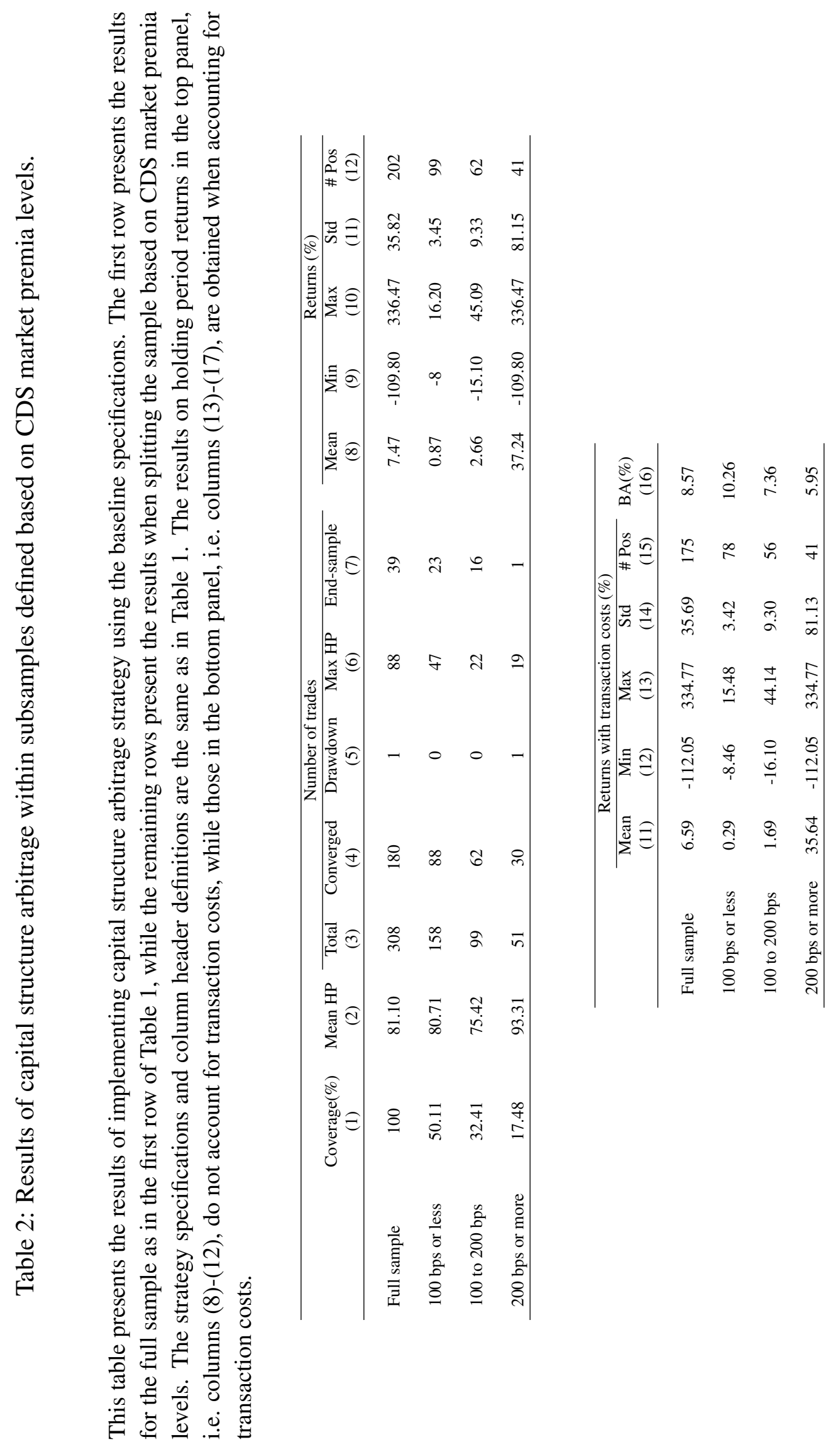




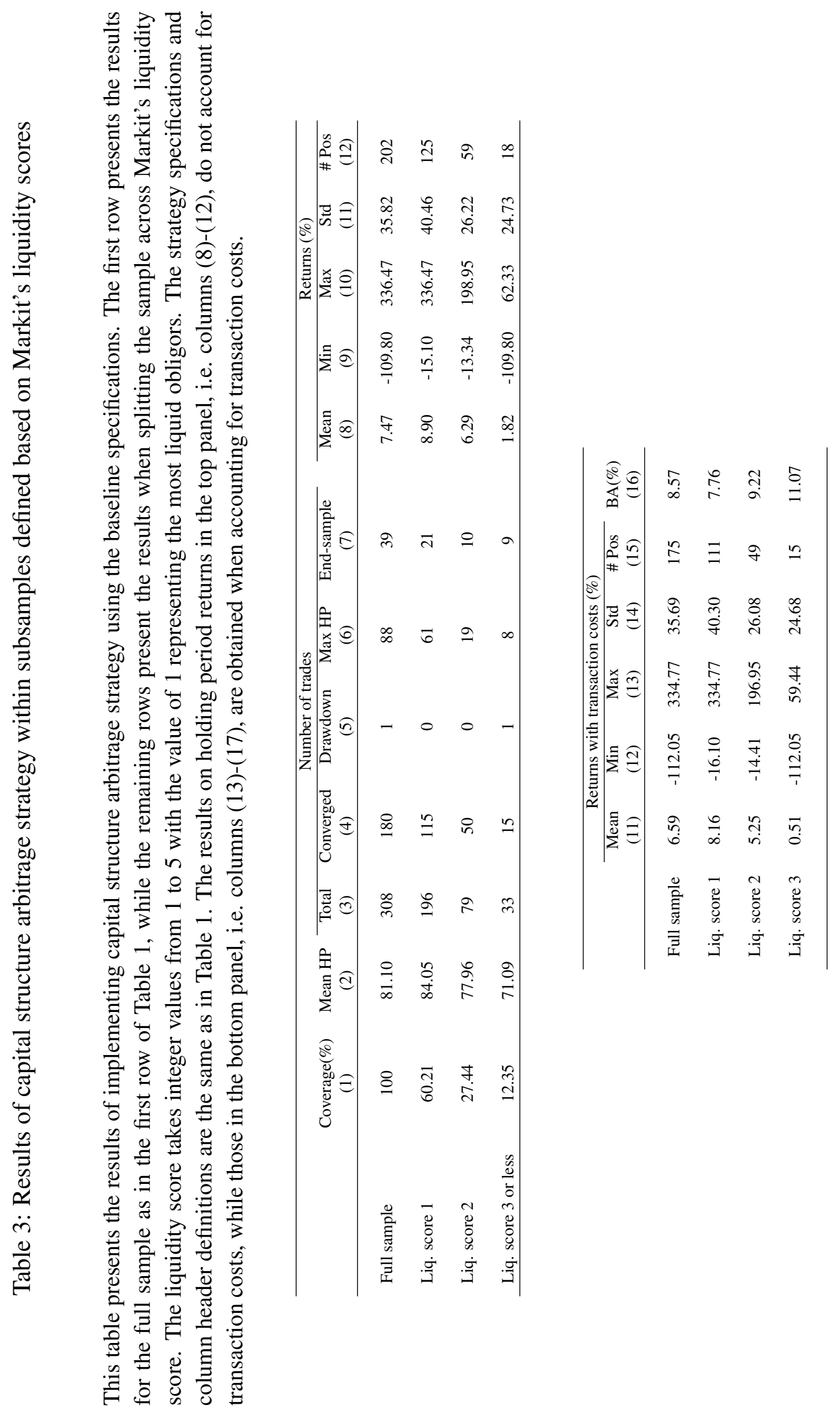




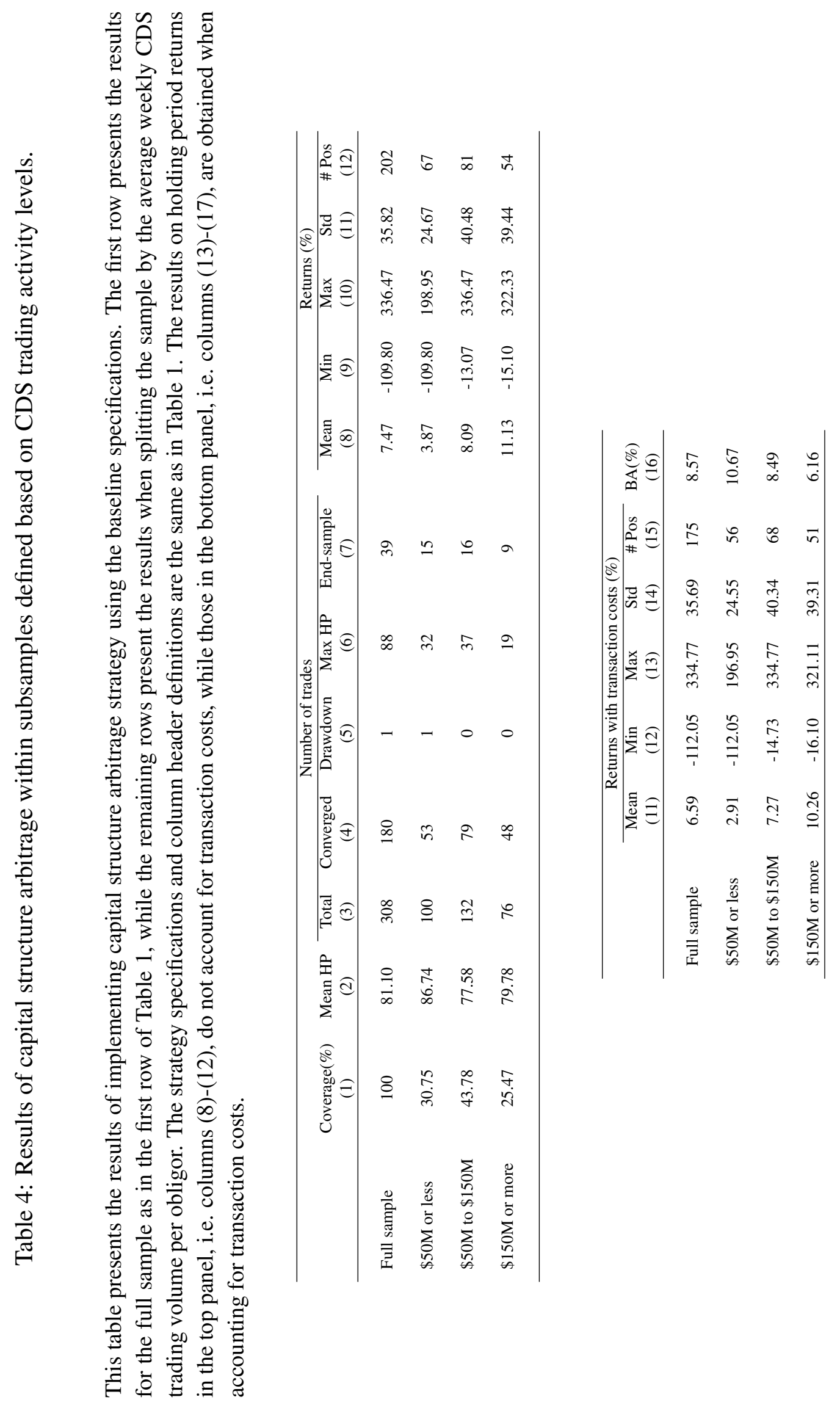




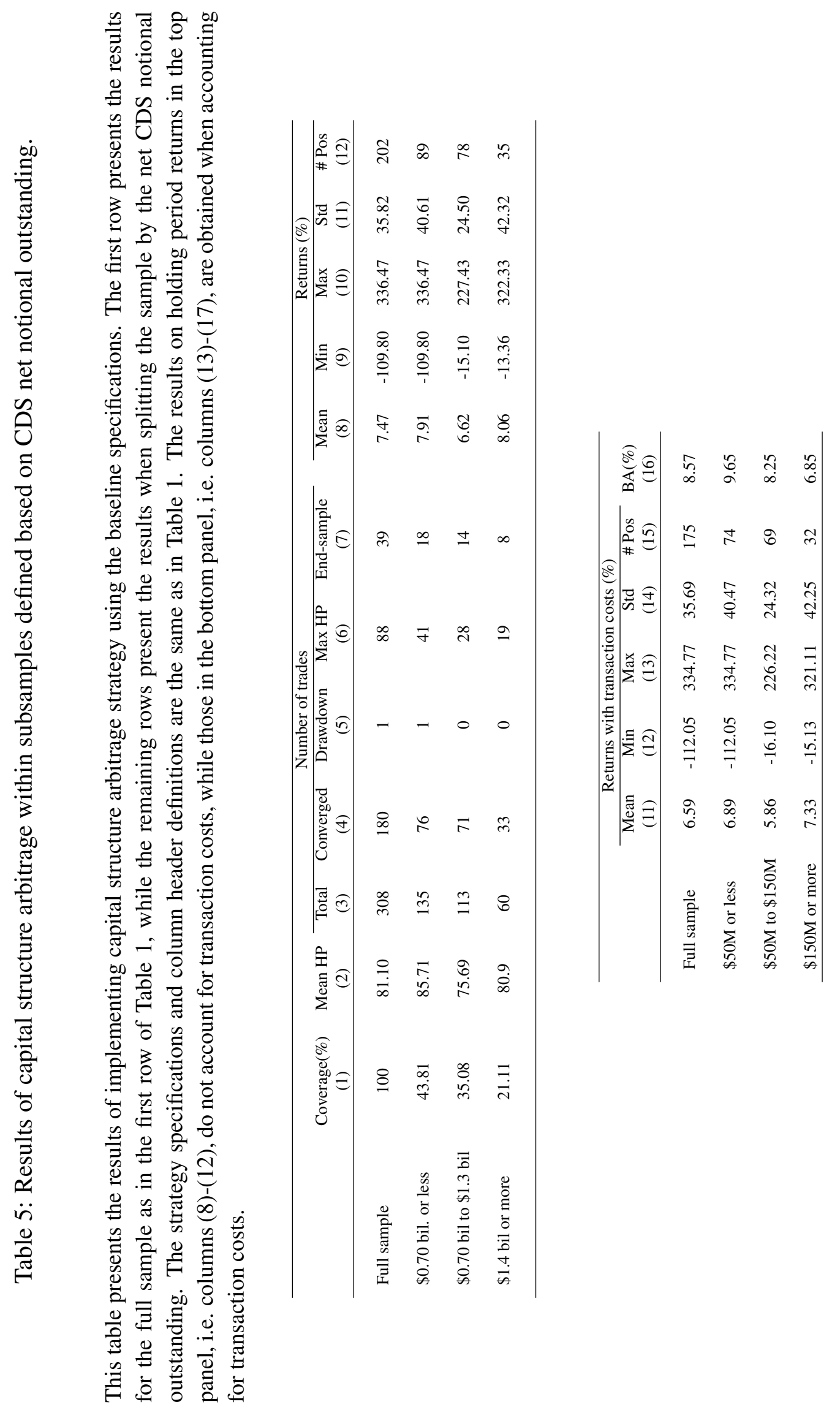


Table 6: Weekly return indices and risk factors.

This table regresses weekly return indices on several risk factors. Two variants of the return indices are considered. 'Index A' is the return index shown in Panel A of Figure 4, which is constructed without rebalancing of trades, while 'Index B' shown in Panel B of Figure 4 is computed with rebalancing of positions to have equal investments in each open trade. As explanatory variables we consider the return of the S\&P 500 index denoted 'S\&P 500', the Bank of America Merrill Lynch corporate bond yield on $\mathrm{BBB}$ rated bonds denoted 'BoAML BBB' and an analogous index for BB rated bonds denoted 'BoAML BB', the self-explanatory 'TED-spread' and the 'VIX' index. Significance at the 10\%, 5\%, and $1 \%$ levels is indicated by $* * *$, and $* * *$, respectively.

\begin{tabular}{lcccc}
\hline & Index A & Index B & Index A & Index B \\
& $(1)$ & $(2)$ & $(3)$ & $(4)$ \\
\hline const & 0.48 & 0.8 & -0.14 & 0.17 \\
& $(0.28)$ & $(0.38)$ & $(-0.07)$ & -0.07 \\
S\&P500 & $0.29^{* * *}$ & $0.26^{* * *}$ & $0.25^{* * *}$ & $0.22^{* *}$ \\
& $(4.43)$ & $(3.23)$ & $(3.32)$ & -2.38 \\
BoAML BBB & $-0.99^{*}$ & -0.47 & $-1.57^{*}$ & -1.05 \\
& $(-1.71)$ & $(-0.66)$ & $(-1.92)$ & $(-1.05)$ \\
BoAML BB & $0.60^{*}$ & 0.26 & $1.31^{*}$ & 0.99 \\
& $(1.7)$ & $(0.6)$ & $(1.62)$ & -1 \\
TED spread & & & 0.34 & 0.44 \\
& & & $(0.26)$ & -0.27 \\
VIX & & & -0.05 & -0.06 \\
& & & $(-0.92)$ & $(-0.79)$ \\
R-squared & 0.15 & 0.08 & 0.16 & 0.09 \\
Adj R-squared & 0.13 & 0.06 & 0.12 & 0.05 \\
P-value mod & 0.00 & 0.01 & 0.00 & 0.05 \\
\hline
\end{tabular}


Panel A: Number of trades executed until a given date.

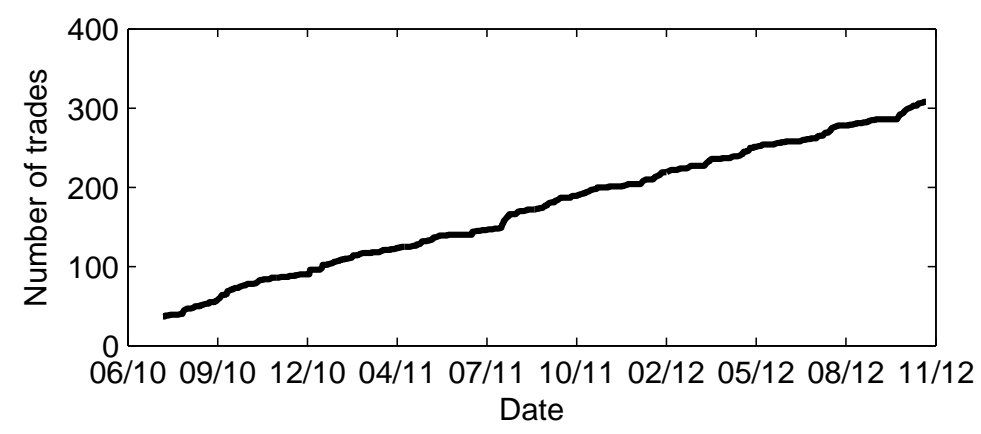

Panel B: Number of trades opened on a given date.

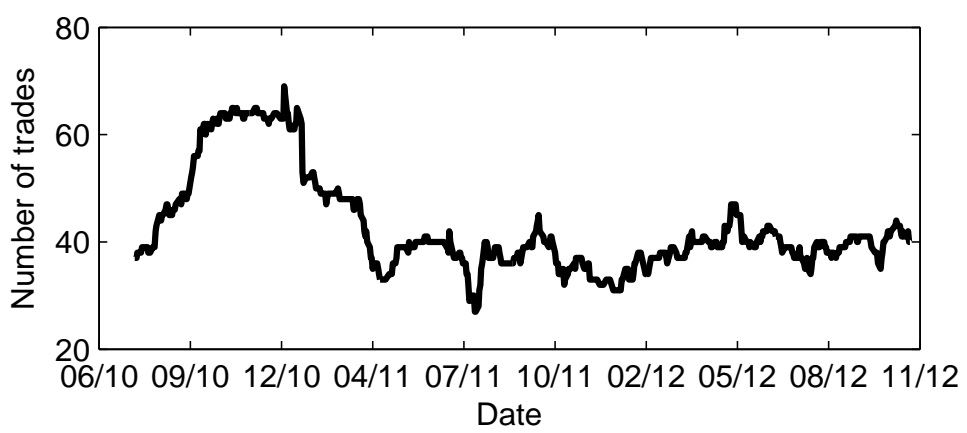

Figure 1: This figure depicts the number of trades in time. Panel A shows the number of trades that have been executed until a given date, whereas Panel B shows only the number of trades that are open on a given date. 
Panel A: Realized profits.

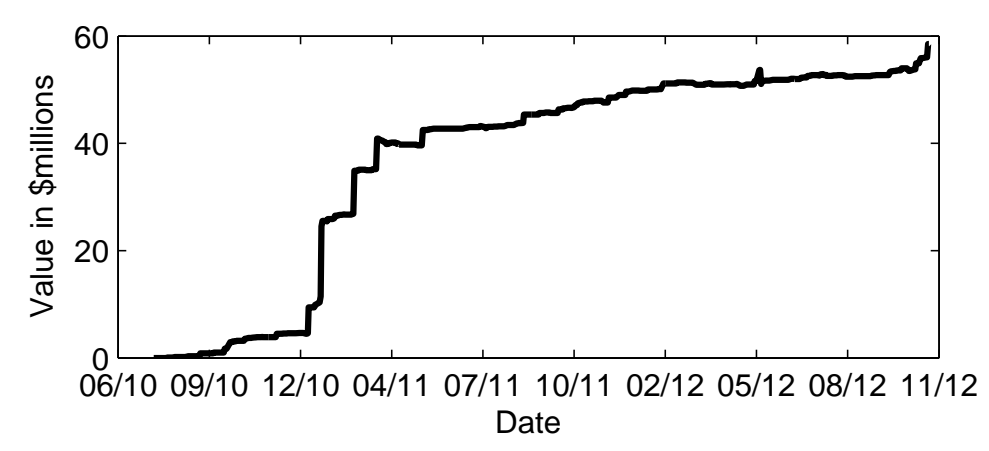

Panel B: The sum of realized profits and the value of currently open contracts.

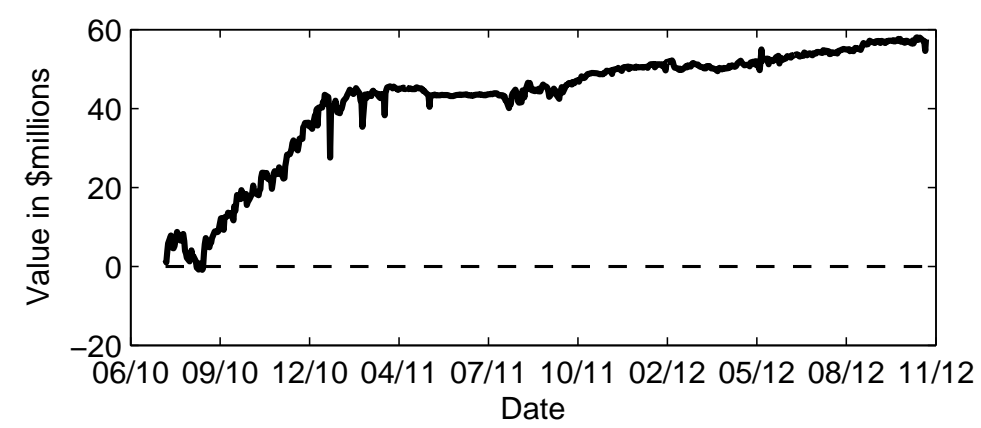

Figure 2: This figure shows the profits from capital structure arbitrage. Panel A depicts the value of all realized profits earned on closed positions, while Panel B depicts the sum of realized profits and the value of all open contracts. 
Panel A: The value of all open trades on a given date.

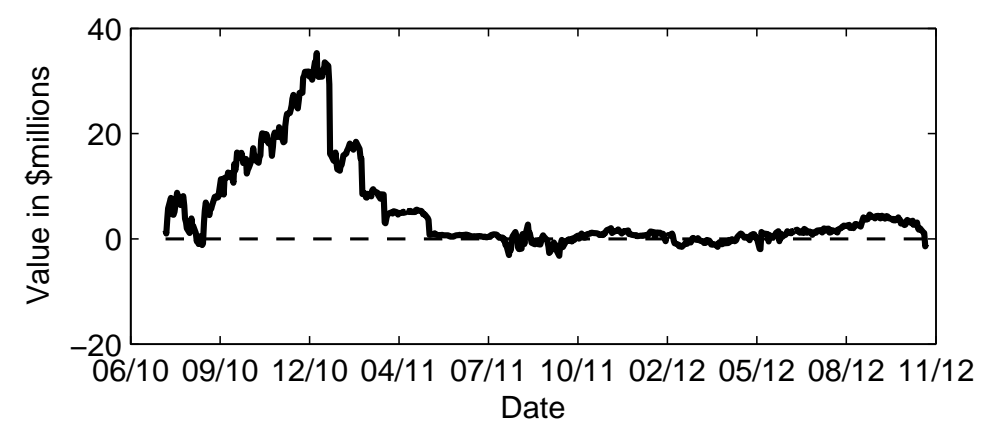

Panel B: The average percentage profit per open trade relative to the initial capital.

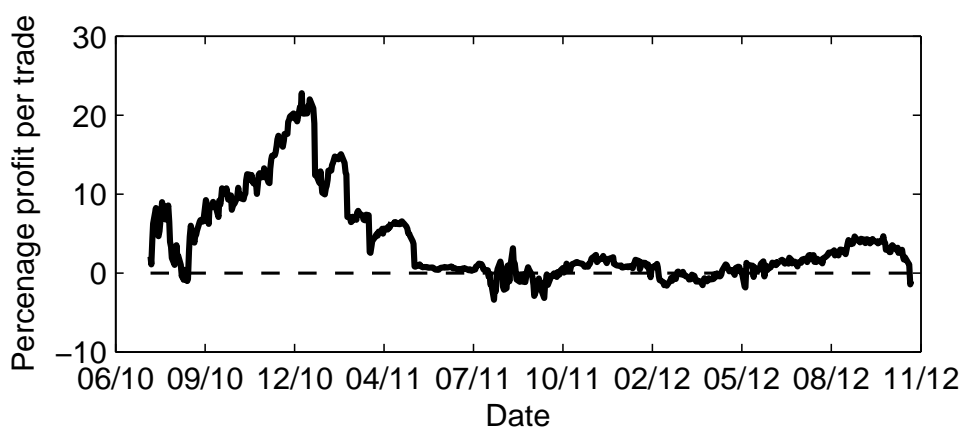

Figure 3: This figure presents the value and profitability of trades that are open on a given date. Panel A shows the sum of the trade values for all open positions in millions of dollars, while Panel B shows the average percentage profit per open trade relative to the initial capital of $50 \%$ of CDS notional. 
Panel A: Weekly return index of open trades without rebalancing of trades.

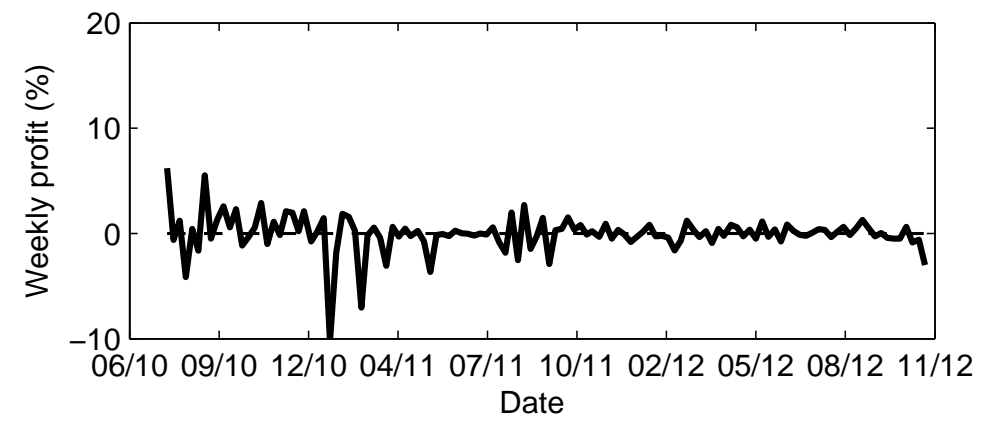

Panel B: Weekly return index of open trades with portfolio rebalancing to have equal investments in each open trade on any given day.

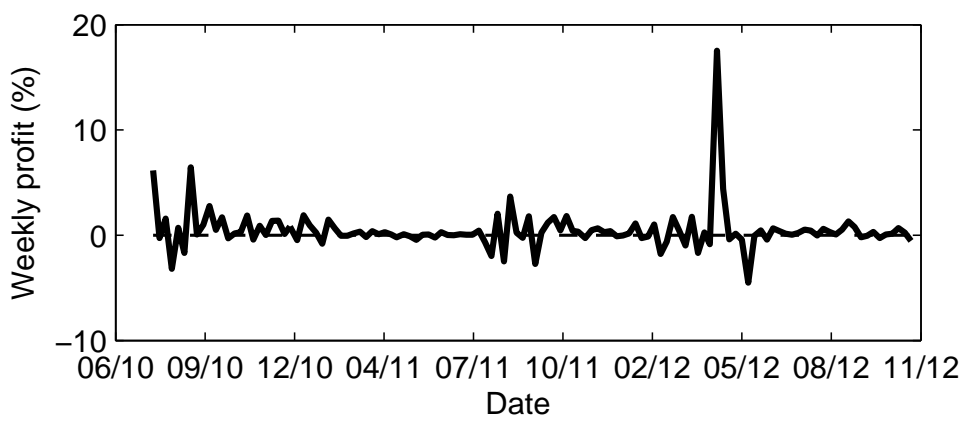

Figure 4: This figure presents weekly return indices summarizing profitability of capital structure arbitrage. Panel A shows the return index constructed by comparing the daily change in the value of all open positions between consecutive days without rebalancing of capital invested in each trade. This means that, for example, a trade that performs poorly has a relatively low weight after some time. In the computation of the returns we assume initial capital of $50 \%$ of the CDS notional traded. New trades are easily incorporated into the index by assuming that each new trade starts with a value of zero and we appropriately adjust the initial capital. Daily returns are aggregated to obtain the weekly returns. Panel B presents weekly return index when assuming that the same amount is invested into each open trade on any given date. This is equivalent to trade rebalancing such that money is being withdrawn from trades that turn profitable, while more money is invested in trades that incurred losses. This approach is motivated by the existing literature, see $\mathrm{Yu}(2006)$ among others. 